over any other form of teaching. A question might arise as to who should be the expert. The answer to this is not the intention of my letter, but I would suggest that the most suitable person to call in would be the medical superintendent of the county asylum of the area in which the patient is residing. It would be impossible for any local authority to suspect him of having any sordid interest in any treatment he might recommend. - I am, Sir, yours faithfully,

Bradfurd-on-Avon, Oct. $28 \mathrm{th}, 1918 . \quad$ Chas. F. S. Flemming.

\section{THE VISITS OF CONSULTANT PHYSICIANS TO PRIVATE SERVICE LUNACY PATIENTS.}

\section{To the Editor of THE LANCET.}

SIR, - I have been in practice now for 45 years ard have done consulting work in mental medicine for over 32 years. During the whole of that period I have seen many patients at the request of their relatives in public asylums, registered hospitals, licensed houses, private care, and in many nursing homes, and until this case my visits have never been opposed but rather welcomed, and I can look back to many very happy hours spent in some of these institutions. I fear from what I hear from several medical men this has not always been the case in their experience.

Not long ago I was asked by a brother of a private service patient in a county asylum to visit and report on his brother's case. I agreed to make this consultative virit and asked him to write to the medical superintendent of the said institution asking for permission for such visit. I also wrote asking the medical superintendent for permission to visit this patient. I received a letter from the medical superintendent stating that such a visit of an outside practitioner to any patient in his asylum would be creating a precedent and that he must refuse permission. I at once pointed out Sec. 47 of the Lunacy Act which dealt with this question and also wrote to the Board of $\mathrm{C}$ introl. The brother of the patient wrote to the Board also, pointing out the same section, and referred to the report of the Select Committee on admission of friends, relatives, and medical men to patients in institutions for the insane. The Board of Cuntrol refused to intervene on the ground that it would create a precedent for an outside practitioner to visit any patient in a public asylum. To this a solicitor replied, saying that unless an order was given for my visit under Sec. 47 of the Act he should immediately apply for a mandamus. A similar request from the wife of the patient was enclosed. By return of post an order for my visit was sent. I wrote to the medical superintendent, telling him the day and time I was coming down, and asking him to let me see the entries in the case-books and the certificates upon which the patient was received as a private service patient. I also asked if he would kindly tell me the best merns of getting quickly from the railway to the asylum. To this letter I received no reply. I arrived at the asylum at about the time stated in my letter, and was told hy the head attendant that he had orders to allow me to see the patient. I asked that I might first see the entries in the case-book $r e$ the case, and also the certificates upon which he was received. His answer was that he had orders not to show me these. I found the patient in bed. I asked why he was in bed, and was told, " To see you." I examined him, and all I could get from him was that he wanted to get back to his wife and family, and to work for them; that he had tried to commit suicide when in a hospiral at Cambridge, and that he felt he was buried alive. I then asked several questions of the attendant in charge, who was unable to reply to them. The medical officer in attendance on the patient refused to see me.

The solicitor then wrote to the Buard of Control, telling them what had happened and asking for another order with special instructions that I was to see the entries in the case-buok and the certificates in respect of the patient, and some medical man. To this letter the Board of Control answered that I had already visited the patient and that there was no reas in for granting another order. The matter is now before counsel as to the next step to be taken.

I admit that the $B$ sard of Control have the right to make the order for such visits as I proposed, and that they reserve that right lest undesirable persons should seek admission to patients in asylums, but I hardly see how a medical consultant can be considered an undesirable visitor. I am, Sir, yours faithfully.

Lionel A. Weathert, M.D.

Winsley House, Bournemouth, Nov. 7th, 1918

\section{PHTHISIS IN FACTORY AND WORKSHOP.}

\section{To the Editor of THE LANCET.}

SIR,-As chairman of the Sabcomittee on Phthisis in Relation to Oscupations appointed by the Medical Research Committee, I would point out that Dr. Benjamin Moore's article in your issue of Nov. 9th was a contribution to the work which is being carried out by this committee of the Medical Research Committee, which was started in 1914 under the chairmanship of Dr. Addison, and the members of which now are Dr. Brownlee, Professor W. Bulloch, Dr. Elgar Collis, Sir Walter Fletcher, Captain Major Green. wood, Dr. Benjamin Moore, and Dr. Leonard Hill. A report of the Subcommitree on the Boot and Shoe Industry was issued by the Medical Research Committee in 1914, and therein the idea of the factory sanatorium was put forward-an idea which arose out of a conversation between Dr. Edgar Collis and Dr. E-slemont. In a paper published in the Proceedings of the Tuberculosis Conference at Leeds in 1913 Dr. Edgar Collis pointed out that the incidence of tuberculosis among adulc males, as compared with that of females, suggested an industrial influence, and that the lack of this difference for males and females in agricaltural areas supported this suggestion. Dr. Brownlee, in a report recently published by the Medical Research Committee, further and extensively examined the incidence of phthisis in rural and industrial districts. Dr. Benjamin Moore now concentrates attention on, and still further elucidates, this important matter. I am, Sir, yours faithfully,

Loughton, Nov, 11th, 1918 LEONARD HILL.

\section{DISPENSARY SUPERVISION IN PULMONARY TUBERCULOSIS.}

To the Editor of THE LANCET.

Sir,-Dr. Geo. Jessel's paper on the above subject in your issue of Oct. 26 th raises the very important question, Are the tuberculosis dispersaries really doing anything to reduce tuberculosis? Dr. Jessel does not, naturally, attempt to answer this question, but only claims that, in his experience, "dispensary supervision has resulted in a considerable measure of success." What may be the kind and degree of this success is not made clear in his paper, as his own figures show that, with the same staff of nurses, the number of cases under observation increased from 1164 in 1916 to 1615 in 1917. That this increase cannot be attributed to greater accuracy in notification Dr. Jessel has himself pointed out.

Dr. Jessel assumes that the possession of a separate bedroom is synonymous with "complete isolation," and from this concludes that "home treatment is thus possible and safe in about 70 per cent. of cases occurring in the industrial areas of Lancashire at any rate." Unfortunately, a long and intimate acquaintance with the industrial conditions of Lancashire has convinced me that this assumption is entirely fallacious. A consumptive who is not bedridden will, of course, make his way to the fire in the "living-roum," and when he becomes bedridden the very warmth of Lancashire people's family affection will effectually prevent his being left in "splendid isolation."

The fact has to be faced that vital statistics show no decline whatever either in the incidence of tub $\rightarrow$ rculosis or the mortality from this cause, and if, as Sir James Bar asserts, our present methods are not only futile but mischievous, it will not do to hide our heads in the sand of such phrases as "stud ying every patient in relation to his environment." Dr. Jessel emphasises the importance of consultation with the "general practitioners," and it is satisfactory to learn that the profession is thus giving a fair trial to the system. I have no doubt that such consultation with experienced practitioners must be of value to officials who, prior to the passing of the Insurance Act, were themselves, as a rule, either general practitioners or medical students.

$$
\text { I am, Sir, yours faithfully, }
$$

Fred E. WYNNE,

Merical Officer of Health, Wigin. President, N.W. Branch, Nov. 7th, 1918. Society of Medic 1 Officers of Health.

The Royal Dental Hospital, Leicester-square, has received a donation of $\$ 300$ from the Alexandru Day Com. mittee, being the amount allocated to this hospital from $H$ Her Majesty Queen Alexandra's Special List. 